\title{
Precision medicine for a man presented with diabetes at 2-month old
}

\author{
Su Fen Ang $\mathbb{D}^{1} \cdot$ Clara Si Hua Tan ${ }^{1} \cdot$ Jessie Choi Wan Fong ${ }^{1} \cdot$ Su Chi Lim ${ }^{1,2,3}$
}

Received: 18 November 2018 / Revised: 31 January 2019 / Accepted: 16 February 2019 / Published online: 19 March 2019

(c) European Society of Human Genetics 2019

\begin{abstract}
A 22-year-old man was referred for continuation of diabetes mellitus treatment. He was first diagnosed with diabetes mellitus 2 months after birth, when he failed to thrive and showed symptoms of diabetic ketoacidosis. There was no family history of diabetes mellitus. The patient did not exhibit the full set of features to be qualified for any developmental delay, epilepsy and neonatal diabetes mellitus (DEND) syndrome. Insulin replacement therapy was initiated; however, management was challenged by wide glycemic excursion, hypoglycemic unawareness and insulin-associated cutaneous lipo-hypertrophy. Reevaluation, including genetic testing, revealed a heterozygous missense p.Arg201Cys variation in the KCNJ11 gene encoding the potassium channel subunit Kir6.2. Successful treatment conversion from insulin to glibenclamide was achieved over an extended period of 2 months (up-titrating to a dose of $1.0 \mathrm{mg} / \mathrm{kg}$ ) in this patient despite his long diabetes duration of 27 years with elimination of hypoglycemia unawareness and achievement of excellent glycemic control sustained over more than 5 years. This case highlights the importance of after having secured a firm genetic diagnosis, to undertake conversion to sulphonylurea with careful dose titration and perseverance over months. Confirmation of variants with functional implications by genetic testing in patients suspected of neonatal diabetes is important for accurate molecular diagnosis and precision-treatment strategy with optimal outcome.
\end{abstract}

\section{Introduction}

Diabetes mellitus is a highly heterogeneous condition. Neonatal diabetes mellitus is defined as diabetes diagnosed in the first 6 months of life and is usually of monogenic etiology [1,2]. Almost half of the afflicted patients suffer from lifelong diabetes (Permanent Neonatal Diabetes Mellitus, PNDM), while the rest exhibit only transient diabetes (Transient Neonatal Diabetes Mellitus, TNDM). Genetic variations giving rise to PNDM has been found to include KCNJ11 (potassium inwardly-rectifying channel, subfamily $\mathrm{J}$, member 11), ABCC8 (ATP-binding cassette, subfamily C

Su Chi Lim

lim.su.chi@ktph.com.sg

1 Clinical Research Unit, Khoo Teck Puat Hospital (KTPH), Singapore, Singapore

2 Diabetes Centre, , Khoo Teck Puat Hospital (KTPH), Singapore, Singapore

3 Saw Swee Hock School of Public Health, National University of Singapore, Singapore, Singapore
(CFTR/MRP), member 8) and INS (insulin) [3-8]. These variations could be inherited or occur spontaneously as a result of germline mosaicism [9, 10]. Variants of KCNJII and $A B C C 8$ disrupt the normal functioning of potassium channels in the pancreatic beta cells, resulting in impaired insulin secretion in response to increased glucose level. The insulin production mechanism, however, is intact but the ability to release insulin in response to increased glucose is impaired. As such, therapy specifically targeting this impairment in secretion may be more desirable instead of insulin replacement which is often used in early-onset diabetes. Sulphonylurea, a drug that induces the closure of potassium channels leading to insulin secretion from the beta cells, can be considered for such variant carriers. Securing an accurate genetic diagnosis in favour of monogenic diabetes forms the basis to embark on treatment conversion.

\section{Subjects and methods}

A 22-year-old man was referred to our Diabetes Centre for re-evaluation of diabetes mellitus treatment. Failure to 
Fig. 1 DNA sequencing results of the patient with neonatal diabetes mellitus. A nucleotide base change from $\mathrm{C}$ to $\mathrm{T}$ was identified which resulted in an amino acid residue change from arginine to cysteine. The genetic variation was determined using Sanger bi-directional sequencing with 2 sets of primers
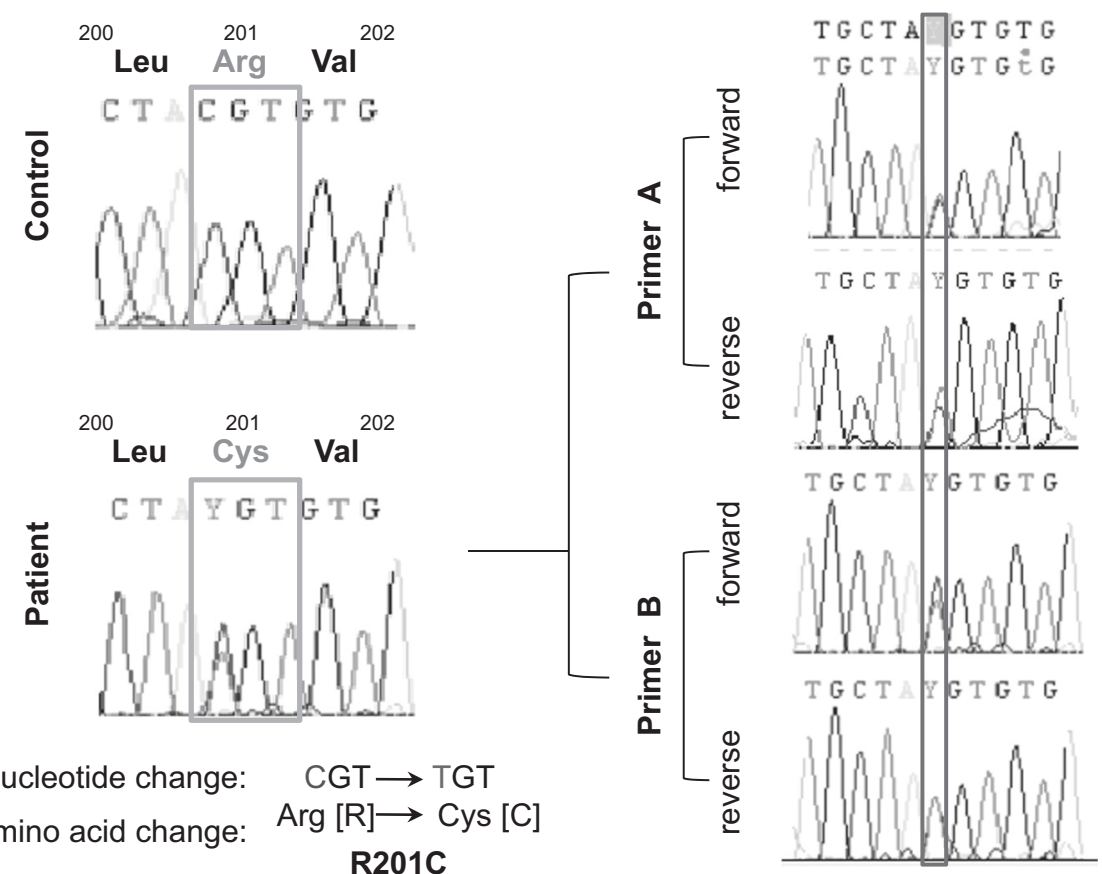

thrive and diabetic ketoacidosis led to the diagnosis of his condition of diabetes mellitus. He was placed on insulin treatment since his diagnosis at 2 months after birth. At the point of referral, he was taking insulin Mixtard (30/70) 42 units in the morning and 22 units in the evening. No family history of diabetes mellitus was indicated. The patient did not exhibit any developmental delay, epilepsy and neonatal diabetes mellitus (DEND) syndrome. He tested negative for glutamate decarboxylase (GAD) antibodies and his $\mathrm{HbA} 1 \mathrm{c}$ level was $8.3 \%$. Fasting blood glucose was high at $21.2 \mathrm{mM}$ with C-peptide below $177 \mathrm{pM}$ (lower limit of detection in our laboratory). Relative unresponsiveness to glucagon was observed in the intravenous $1 \mathrm{mg}$ glucagon challenge with C-peptide less than $177 \mathrm{pM}$. The patient also exhibited lipohypertrophy over insulin injection site and has some degree of hypoglycemia unawareness. Genetic testing and analysis was therefore suggested to investigate potential variation(s) for monogenic diabetes in this patient. Genetic testing was performed for this patient when he was 26 years old.

DNA from the patient's blood sample was extracted and subjected to Sanger sequencing using primers designed against 2 hotspot variation regions, valine-59 and arginine201, of the KCNJ11 gene.

The data were submitted to LOVD (Leiden Open Variation Database) with Individual ID 00213040.

\section{Results}

A heterozygous variation was identified at the amino acid position of 201 with a residue change from arginine to cysteine [NM_000525.3(KCNJ11):c.601C > T p.(Arg201Cys)] (Fig. 1). This variant has been shown to reduce theability of potassium channels in the beta cells to close upon an increase in ATP as a result of glucose metabolism $[11,12]$. The cells remain hyperpolarized and cannot release insulin in response to the increased glucose. Previous clinical studies have shown that patients with variations in the KCNJ11 gene can be successfully converted to oral sulphonylurea treatment [13-16]. A treatment conversion was therefore proposed, and the patient agreed to undergo the switch at 27 years old.

Before in-patient treatment conversion, a continuous glucose monitoring system (CGMS) was used to determine the glycemic control profile of the patient under insulin treatment (Fig. 2). It was noted that the patient encountered periods of hyper- and hypo-glycaemia under the existing insulin treatment, suggesting that glycemic control could be improved. The patient was warded for 6 days for administration of the conversion protocol as published by Pearson et al. [16]. The protocol was continued in an outpatient setting and the first improvement in glucose level control with the oral sulphonylurea, glibenclamide, was observed 6 weeks from the beginning of the conversion (without insulin). Further titration of glibenclamide to $25 \mathrm{mg}$ per day was carried out and $\mathrm{HbAlc}$ levels remained below $7 \%$ under this reduced dose.

Measurements of blood glucose during different treatment regimens were performed (Fig. 3a). An optimal level was achieved using only glibenclamide treatment by the end of 3 months. HbA1c levels also went down to an acceptable level below $7 \%$ with further titration of glibenclamide 
Tue $18 / 10(\mathrm{mmol} / \mathrm{L}) \quad$ Sensor

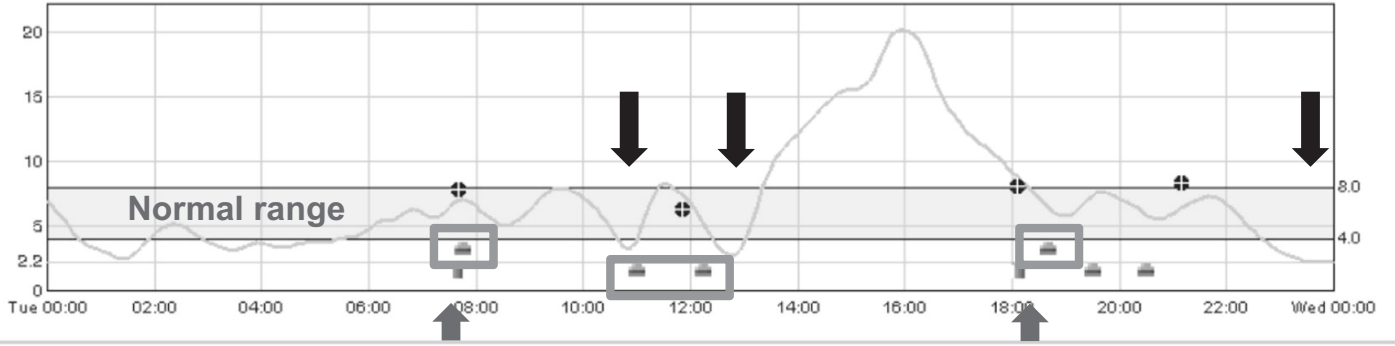

Wed 19/10 (mmol/L) Sensor __ Use Clinical Judgement

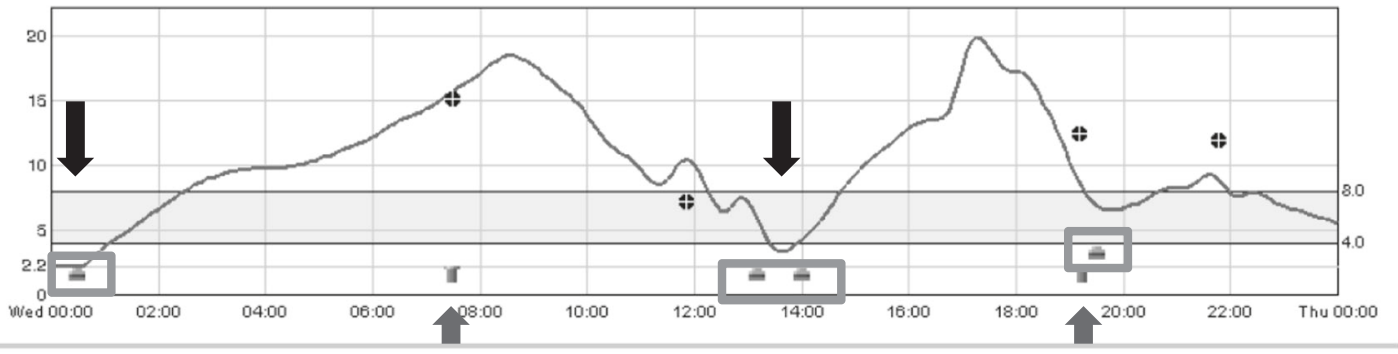

Thu 20/10 (mmol/L) Sensor __ Use Clinical Judgement

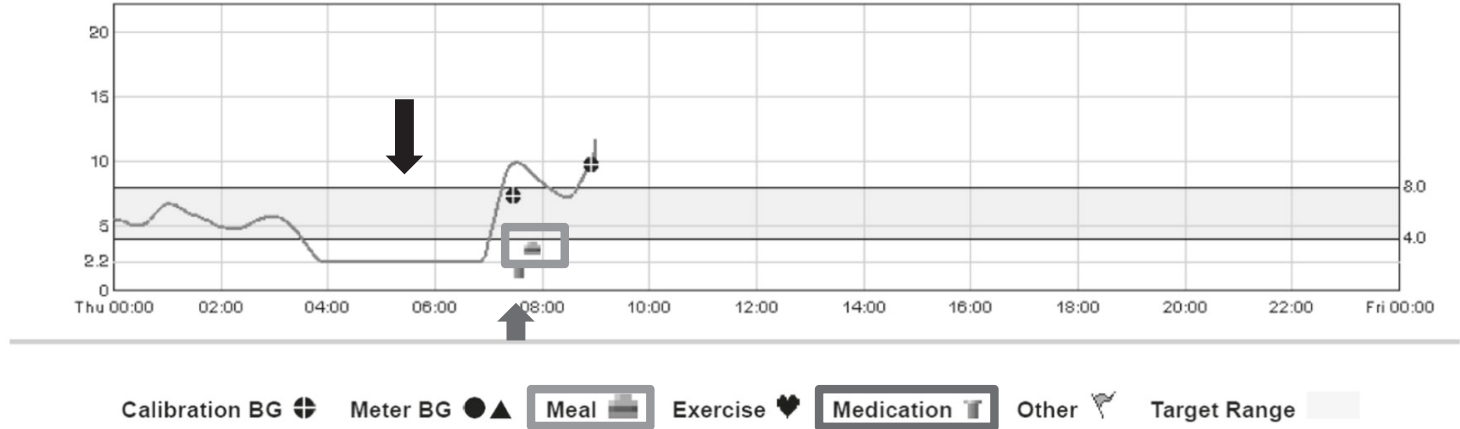

Fig. 2 Continuous glucose monitoring system (CGMS) showing glucose level fluctuations over 3 days. Red arrows denote insulin administration and blue arrows indicate periods of hypoglycemia

(Fig. 3b). The patient denied further post-conversion tests like CGMS and mix-meal challenge to assess his glycemic profile so these data were not available for further consideration and analysis.

\section{Discussion}

We describe here a case of successful treatment conversion from insulin to sulphonylurea for $K C N J 11$ neonatal diabetes despite a diabetes duration of 27 years. This was accomplished with a modified protocol in which glibenclamide was up-titrated to $1.0 \mathrm{mg} / \mathrm{kg}$ over a period of 2 months to progressively achieve an optimal clinical response. Once glycemic target has been achieved and sustained, step-wise gradual down-titration to $25 \mathrm{mg}$ daily (i.e. $0.4 \mathrm{mg} / \mathrm{kg}$, in contrast with the initiation high dose of $1 \mathrm{mg} / \mathrm{kg}$ ) was successful. This was much closer to the usual recommended daily maximum dose of up to $20 \mathrm{mg}$ daily for adults with Type 2 diabetes to avert side effects associated with highdose sulphonylurea like teeth discoloration and diarrhea $[17,18]$. At this reduced dose, glycemic control was sustained in this patient with absence of hypoglycemia since 2011. Babiker et al. observed that patients who had unsuccessful conversions had a longer duration of diabetes as compared to those who were successful (mean 18.2 vs 3.4 years) [17, 19]. Given that clinical responsiveness to sulphonylureas can be affected by duration and may vary with individuals (as observed in our patient), our experience suggests that for $K C N J 11$ variant carriers with a longer diabetes duration, the conversion protocol may have to be further individualized and that a successful conversion is still possible even for those with duration of over 18 years. 
Fig. 3 a Blood glucose levels of patient at different pre-meal periods. Insulin was gradually reduced with increased glibenclamide dosage. Glibenclamide dosage was titrated down further after complete conversion from insulin. b HbA1c levels of patient were monitored. Green arrow denotes the point of complete switch to glibenclamide. BF breakfast, L lunch, D dinner, BT bedtime
A

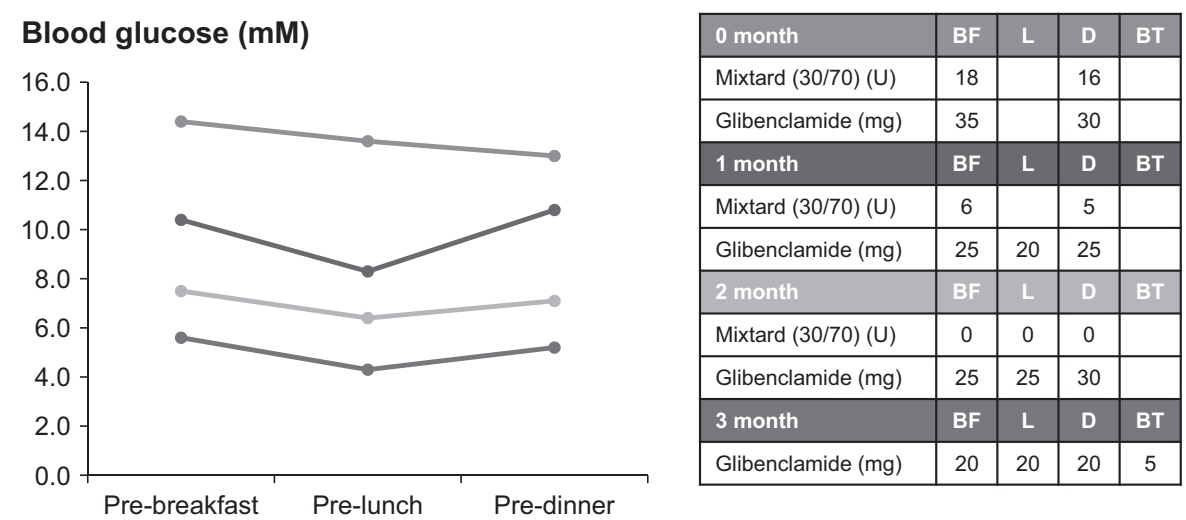

B

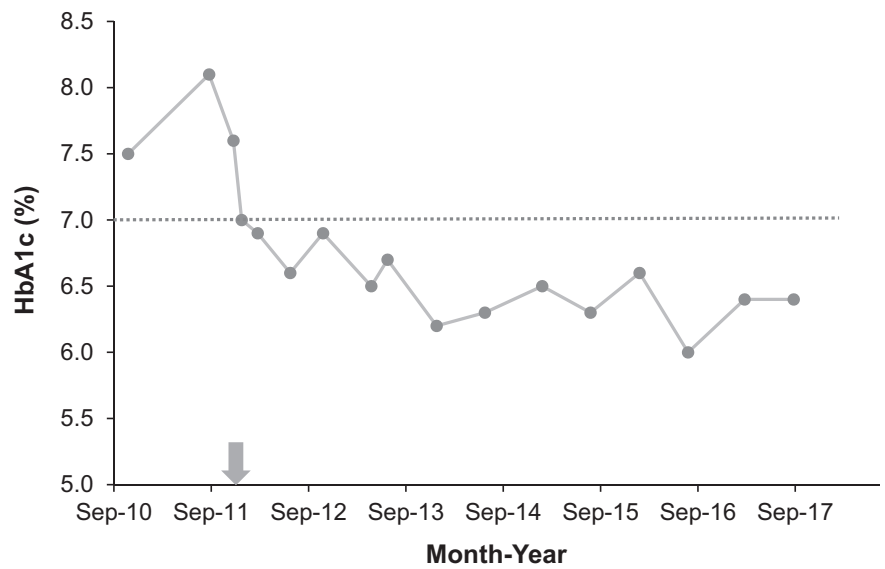

As we have adopted a step-wise approach to identify the causal variant starting with the 2 hotspot regions in $K C N J 11$, we have not screened further for additional variants in $K C N J 11$ and other genes such as $A B C C 8$ and INS that may also cause neonatal diabetes. Therefore, we cannot rule out the possibility that the patient may carry more than one function-affecting variant in multiple genes and that the delayed responsiveness to sulphonylureas may be attributed to the presence of other genetic variations which remains to be determined.

In summary, evaluation of both genetic variation and clinical presentation (duration of diabetes) is important for successful implementation of precision medicine in KCNJ11 neonatal diabetes.

Acknowledgements This study is funded by National Healthcare Group (NHG)-Khoo Teck Puat Hospital (KTPH) Small Innovative Grants: SIGI/13038, SIGII/14001 and STAR17201. We would also like to thank the patient for giving consent to share his case for the benefit of improving diabetes care.

\section{Compliance with ethical standards}

Conflict of interest The authors declare that they have no conflict of interest.
Publisher's note: Springer Nature remains neutral with regard to jurisdictional claims in published maps and institutional affiliations.

\section{References}

1. Iafusco D, Stazi MA, Cotichini R, Cotellessa M, Martinucci ME, Mazzella M, et al. Permanent diabetes mellitus in the first year of life. Diabetologia. 2002;45:798-804.

2. Edghill EL, Dix RJ, Flanagan SE, Bingley PJ, Hattersley AT, Ellard S, et al. HLA genotyping supports a nonautoimmune etiology in patients diagnosed with diabetes under the age of 6 months. Diabetes. 2006;55:1895-8.

3. Gloyn AL, Pearson ER, Antcliff JF, Proks P, Bruining GJ, Slingerland AS, et al. Activating mutations in the gene encoding the ATP-sensitive potassium-channel subunit Kir6.2 and permanent neonatal diabetes. N Engl J Med. 2004;350:1838-49.

4. Babenko AP, Polak M, Cave H, Busiah K, Czernichow P, Scharfmann R, et al. Activating mutations in the ABCC8 gene in neonatal diabetes mellitus. N Engl J Med. 2006;355: 456-66.

5. Edghill EL, Flanagan SE, Patch AM, Boustred C, Parrish A, Shields B, et al. Insulin mutation screening in 1,044 patients with diabetes: mutations in the INS gene are a common cause of neonatal diabetes but a rare cause of diabetes diagnosed in childhood or adulthood. Diabetes. 2008;57:1034-42.

6. Stoy J, Edghill EL, Flanagan SE, Ye H, Paz VP, Pluzhnikov A, et al. Insulin gene mutations as a cause of permanent neonatal diabetes. Proc Natl Acad Sci USA. 2007;104:15040-4. 
7. Colombo C, Porzio O, Liu M, Massa O, Vasta M, Salardi S, et al. Seven mutations in the human insulin gene linked to permanent neonatal/infancy-onset diabetes mellitus. J Clin Invest. 2008;118: 2148-56.

8. Edghill EL, Flanagan SE, Ellard S. Permanent neonatal diabetes due to activating mutations in ABCC8 and KCNJ11. Rev Endocr Metab Disord. 2010;11:193-8.

9. Gloyn AL, Cummings EA, Edghill EL, Harries LW, Scott R, Costa $\mathrm{T}$, et al. Permanent neonatal diabetes due to paternal germline mosaicism for an activating mutation of the KCNJ11 Gene encoding the Kir6.2 subunit of the beta-cell potassium adenosine triphosphate channel. J Clin Endocrinol Metab. 2004;89:3932-5.

10. Edghill EL, Gloyn AL, Goriely A, Harries LW, Flanagan SE, Rankin J, et al. Origin of de novo KCNJ11 mutations and risk of neonatal diabetes for subsequent siblings. J Clin Endocrinol Metab. 2007;92:1773-7.

11. Proks P, Antcliff JF, Lippiat J, Gloyn AL, Hattersley AT, Ashcroft FM. Molecular basis of Kir6.2 mutations associated with neonatal diabetes or neonatal diabetes plus neurological features. Proc Natl Acad Sci USA. 2004;101:17539-44.

12. Proks P, Girard C, Ashcroft FM. Functional effects of KCNJ11 mutations causing neonatal diabetes: enhanced activation by MgATP. Hum Mol Genet. 2005;14:2717-26.

13. Sagen JV, Raeder H, Hathout E, Shehadeh N, Gudmundsson K, Baevre $\mathrm{H}$, et al. Permanent neonatal diabetes due to mutations in KCNJ11 encoding Kir6.2: patient characteristics and initial response to sulfonylurea therapy. Diabetes. 2004;53:2713-8.
14. Zung A, Glaser B, Nimri R, Zadik Z. Glibenclamide treatment in permanent neonatal diabetes mellitus due to an activating mutation in Kir6.2. J Clin Endocrinol Metab. 2004;89: 5504-7.

15. Klupa T, Edghill EL, Nazim J, Sieradzki J, Ellard S, Hattersley AT, et al. The identification of a R201H mutation in KCNJ11, which encodes Kir6.2, and successful transfer to sustained-release sulphonylurea therapy in a subject with neonatal diabetes: evidence for heterogeneity of beta cell function among carriers of the R201H mutation. Diabetologia. 2005;48: 1029-31.

16. Pearson ER, Flechtner I, Njolstad PR, Malecki MT, Flanagan SE, Larkin B, et al. Switching from insulin to oral sulfonylureas in patients with diabetes due to Kir6.2 mutations. N Engl J Med. 2006;355:467-77.

17. Bowman P, Sulen Å, Barbetti F, Beltrand J, Svalastoga P, Codner E, et al. Effectiveness and safety of long-term treatment with sulfonylureas in patients with neonatal diabetes due to KCNJ11 mutations: an international cohort study. The Lancet Diabetes \&. Endocrinology. 2018;6:637-46.

18. Kumaraguru J, Flanagan SE, Greeley SAW, Nuboer R, Støy J, Philipson LH, et al. Tooth discoloration in patients with neonatal diabetes after transfer onto glibenclamide. Diabetes Care. 2009;32:1428.

19. Babiker T, Vedovato N, Patel K, Thomas N, Finn R, Mannikko R, et al. Successful transfer to sulfonylureas in KCNJ11 neonatal diabetes is determined by the mutation and duration of diabetes. Diabetologia. 2016;59:1162-6. 